\title{
An adventurous journey: Social workers guiding customer service workers on the welfare frontline
}

\author{
Greg Hall ${ }^{1,2}$, Jennifer Boddy ${ }^{1}$ and Lesley Chenoweth ${ }^{1}$
}

${ }^{1}$ Griffith University, Australia

${ }^{2}$ Children and Family Programs, Queensland Department of Education and Training, Australia
AOTEAROA

NEW ZEALAND SOCIAL WORK 28(3), 26-36.

CORRESPONDENCE TO: Greg Hall

greg.hall@griffithuni.edu.au

\section{ABSTRACT}

INTRODUCTION: This paper explores a reform to worker relationships at the frontline of the Australian income support and government service provider (Centrelink). Reform involved social workers providing guidance to customer service workers and working closely with them in order to improve interactions with people seeking assistance.

METHODS: A case study traced reform in two Centrelink offices over one year, and included semi-structured interviews and observations with social workers and customer service workers. A thematic analysis highlighted the nature of changes to worker relationships over time, and how new relationships supported new organizational practices.

FINDINGS: Customer service workers initially reported both anxiety and excitement, expressing admiration of social workers' skills and knowledge. Over time, they emphasised the inspiration and interpersonal support social workers provided them, how this helped them deal with difficult situations and was missed when not available. Social workers' initial scepticism around demands on their time and challenges to their professionalism gave way (in part) to a sense of influencing and guiding workers towards more humanising interactions, although some concerns and organizational tensions remained.

CONCLUSION: Guidance to other workers is a form of leadership which fits well with social work's relational, supportive potential. Tensions in the welfare context mean that providing guidance is both rewarding and challenging, taking social workers on an adventurous journey involving adversity and (self) discovery.

KEYWORDS: relational social work; income support; customer service; professional identity

\section{Introduction}

Challenges in late modern social welfare settings can make the idea of social workers as inspirational change agents appear unrealistic (Marston \& McDonald, 2012). Increasing managerialism, machine-like processing and shallow customer service orientations pose daunting obstacles for social workers (Rogowski, 2010). In large government organizations human issues can become lost in traffic control, where market outcomes overshadow humanistic support (McDonald \& Chenoweth, 2009). For a social worker in this situation, their expectations may not match the realities of limited influence, hostility, confusion and helplessness. Rather than inspired, workers in this environment may feel closer to Kafka's (anti)hero in The Castle,

A lot of things here seem designed to put one off, and when a person first arrives the obstacles look insuperable... ...circumstances, the vast amount of 
work, the way officials are employed in the castle, the difficulty of getting hold of them......Who, on his own, however great a worker, could gather all the strands of even the most minor incident together on his desk at one time? (Kafka, 1997, pp. 232-7)

Whilst the organizational setting can constrict and complicate social work practice in Kafkaesque ways, social workers can also influence the organization they work in, particularly through the relationships they build (Hughes \& Wearing, 2013). Encouraging organizational and network responsiveness through developing supportive and anti-oppressive relationships has been a focus of a range of relationally oriented theory influencing social work such as strengths (McCashen, 2005), network (Trevillion, 1999), dialogical (Seikkula \& Arnkil, 2006) and relational social work (Folgheraiter, 2004).

Recent examples of innovative relational practice have seen social workers challenge dehumanising approaches in social security settings (Tonkens \& Verplanke, 2013) and expose the development there of a 'welfare dead zone' where people needing help are increasingly alienated from services and caught in a dangerous cocktail of isolation and disaffection (Global Agenda for Social Work and Social Development, 2014, p. 28). Our own research explored how social workers were involved in and influenced some recent change attempts and changing relationships in the Australian income support setting (Centrelink).

\section{Background}

Centrelink is predominantly staffed by customer service workers who deal with enquiries and requests around payments and claims. Customer service workers interview people in severe financial hardship experiencing difficulties in everyday living, and often in crisis. Difficulties and crises are revealed (and obscured) in customer service interactions, and there is significant research literature which has highlighted the complicated nature of such interactions in Centrelink (Eardley et al., 2005; Howard, 2012). There is longstanding criticism that Centrelink's service framework simplistically frames people in need of complex support as 'customers', and that interactions with Centrelink can exacerbate distress and tension for people seeking assistance (Murphy et al., 2011). There is also some evidence that its customer service approach involves tension and distress for workers (Howard, 2012, Kennedy \& Corliss, 2008) who might benefit from access to social workers for advice and guidance in their work (Diaz, 2008).

Social workers have operated in the Australian social security context for over seventy years, with over six hundred currently employed as 'professional officers' in Centrelink. Whilst this is a small proportion (2-3\% of overall staff), social workers occupy relatively senior operational levels, working in small detached teams in local offices, processing and call centres.

Some interactions between people accessing Centrelink and customer service workers may touch on clear triggers which result in a referral to a social work team (for example, around payments related to escaping domestic violence). However, customer service workers also encounter many situations which are unclear and where referrals are dependent on how an interaction unfolds at the frontline. Ambiguity may arise where the service interaction itself invites confusion or distress, particularly given increasingly automated claim processes and the mismatch between tightening social security policy conditions and expanding needs for income support with diverse groups of people seeking assistance (Murphy et al., 2011). This can lead to mistrust as customers present as confused, distressed or angry following cancelled or suspended payments, and where they perceive that their needs are not being responded to (Murphy et al., 2011). 


\section{Change Attempts Involving Social Workers in Centrelink}

In this complicated and potentially volatile setting, an innovation was introduced in 2011/12 whereby social workers in a number of Centrelink sites began to work more closely with customer service workers (Australian Department of Human Services, 2013). Reforms expanded on some previous local projects which involved social workers working with customer service staff to assist particular groups of clients in need (Hall, Boddy, Chenoweth, \& Davie, 2012). Reforms posed possibilities for improving organizational responses to difficult and distressing human situations through improving the network of relationships surrounding frontline customer service. In practice, this meant social workers would work directly with customer service staff, provide coaching and guidance, and work collaboratively on complex cases at an early stage rather than through a detached referral process.

New arrangements involved substantial resourcing for customer service workers. This was to give them more time with people seeking assistance, time to consult and engage with social workers regularly, and to offer people better access to social workers for more comprehensive support. For social workers, new arrangements positioned them as the key support for customer service workers (but involved only limited resourcing, with expectations that they could draw on additional support from customer service workers to lessen some of their overall workload). Changes drew social workers into challenges at the frontline, and this paper traces these developments drawing on a case study of two sites undertaken for around one year as changes unfolded.

\section{Method}

The question of how relationships developed between social workers and customer service workers was considered through a case study of two sites involved in changes, one regional and one metropolitan. The case study included interviews with social workers and customer service workers, as well as observations during site visits. We have also pursued consideration of other perspectives, including people accessing assistance and Centrelink managers (Hall, Boddy, \& Chenoweth, 2014; Hall, Hadson, Boddy, \& Chenoweth, 2014), but focus in this paper on worker relationships.

A case study approach was used to afford a close involvement with participants over an extended period of time and was in keeping with our conceptualization of relationships as constructed "in a situation" (Folgheraiter, 2004, p.130). Whilst often criticised for a lack of explanatory power, the rich picture of participant perspectives and changes over time, characteristic of case study, is particularly suited to understanding dynamic environments involving new and untested experiences (Flyvbjerg, 2006). A rich engagement with workers' perspectives was central to our research interest in their engagement in a potentially humanising service, and provided a basis for conceptualising new developments in human terms.

Twenty four worker interviews were undertaken involving fourteen workers in total. Semi structured interviews were conducted during site visits after workers had been involved in arrangements for some months (typically no more than three months) and again after they had been involved for around 9-12 months. Eight customer service staff and six social workers participated (from a possible pool of ten and eight respectively). All interviews and site visits were undertaken by the first named author, who subsequently participated in reflective discussions with the remaining authors to refine concepts and cross-check high level themes prior to a more detailed analysis.

Analysis of interview recordings and notes, with assistance from NVivo10, focused on comparing and contrasting perspectives 
and highlighting themes within a matrix (Miles \& Huberman, 1994) featuring three stages: reflections on prior history of service provision in the sites; views on early experiences over the first few months of change, and perspectives on later experiences (approaching the end of the first year). An initial coding process established a large set of codes which was then categorised according to several overarching themes (Miles \& Huberman, 1994). A narrative of findings was developed for reporting based on this themed timeline of changes. This narrative references participants extensively in their own words, reflecting an attention to polyphony and to minimising researcher bias by including multiple voices directly in reporting - a process discussed at length elsewhere (Hall, Boddy, \& Chenoweth, 2014). Some identifying details not relevant to findings have been altered to preserve anonymity. This research was approved through the Griffith University Ethics Committee.

Some limitations arose around accessibility, meaning that one research participant from each group was unavailable for a later interview and one from each group unavailable for an early stage interview. The two sites involved were chosen because they undertook early implementation of new arrangements (which were planned to roll out across 44 sites by 2014/15). These sites may not have been representative, however later interviews with senior managers who covered multiple sites indicated that findings were relevant to experiences in other offices.

\section{Findings}

\section{Reflections on previous service arrangements}

It's always about the queue...about pumping them through, excuse the expression, I know it's horrible...but that's what it's about. (Renee, Customer Service Worker)

It's an environment that's run by numbers and figures and I.T.
[Information Technology]. (Lisa, Social Worker)

That the social security environment could be oppressively process oriented, machine-like and dominated by information technology was a view shared by workers in early interviews when reflecting on their past work. This is not unexpected, given previous research literature has detailed the anxieties of customer service workers (Howard, 2012; Kennedy \& Corliss, 2008) and challenges for social workers in this environment (Dearman, 2005; McDonald \& Chenoweth, 2009). What was perhaps of more significance was the apology and the clear desire amongst customer service workers to provide a more balanced service which did not favour a business of quick transactions over human factors. Customer service workers reflected that processing people quickly was about organizational drivers rather than meeting the needs of people.

My personal experiences from working for [Centrelink] is we're very transaction based...so 'get them in get them out... don't let them talk too much'... For every transaction we do in [the computer system] we get so many funding dollars. (Mary, Customer Service Worker).

Some customer service workers appeared highly concerned about this and were also conscious of having limited knowledge and capacity to help.

I've always had customers telling me their issues... and before, I never knew what to do. To say have you thought about this or that, to have those resources...a stepping stone to where they want to go. (Felicity, Customer Service Worker)

Customer service workers also drew connections between customer experiences and their own sense of pressure working in that environment.

'Don't let them talk too much'...I personally have been stopped...have 
been told I have to stop customers from talking...[The] manager said to me I need to be more \{pause, appears upset\}.. computer based. (Ralph, Customer Service Worker)

In Ralph's case, he elaborated a scenario before recent changes where he had attempted to engage with a customer who wanted to share a positive experience and been advised (electronically) not to.

One situation, I had this man, he was on DSP [Disability Support Pension] and had been for years... He got a job and so he's come in to tell us about his earnings...and I'm like, 'fantastic', you know, 'this is great' ... and he was telling me about it... so I was coding his stuff but also discussing with him... and I got a couple of messages from my manager saying 'you need to move on...you need to get rid of him'...(Ralph, Customer Service Worker)

\section{Excitement and scepticism}

It is perhaps not surprising then, that customer service workers expressed excitement at the prospect of being able to listen to people and work more closely with social workers. Customer service workers perceived social workers as highly skilled and knowledgeable, particularly around the use of community resources.

Having them [social workers] there is going to be massive, just for their knowledge. (Mary, Customer Service Worker)

However, social workers expressed an initial reticence around new arrangements, and stressed the pressures they already experienced to manage workloads and not fall into a processing approach themselves. Although they shared a concern about service provision in the front office and the potential for people to fall through the cracks, they were also concerned that customer service staff might be viewed as pseudo-social workers, engage in what they saw as risky practices or potentially take over their roles. These concerns were heightened by the fact that additional resourcing was largely provided organizationally for customer service staff.

We didn't get resources... and this is a very big pressure on the social work service. That [it] is not recognised in the funding...if you want to do a good job, to respond to what needs to be at the front. (Nicole, Social Worker)

As a social worker probably the biggest thing for me is that without that ongoing support... staff will take the conversations too far and not know how to bring it back and not know what to do. (Lisa, Social Worker)

Social workers' scepticism was also inspired by experiences of a longstanding organizational push towards phone-based work and online service delivery, which they felt represented a move away from the development of local relationships.

\section{Experiences of change}

They [the social workers] were always very remote before...you knew them and you'd say ' $\mathrm{Hi}^{\prime}$, but that was about the extent of it. It's a lot more personalised now, a lot more give and take. It's a much better relationship(Felicity, Customer Service Worker)

Both groups described a significant change as new arrangements were implemented. Social workers were involved in the delivery of initial training sessions over the course of one week. The sessions covered issues and services in the local community, paying attention to people's strengths, and relating to people in a more open and supportive conversational manner. Over the first few months, social workers assisted (variably) with visits to and from community agencies, and provided weekly one-hour coaching sessions with customer service workers, although this also varied over time due to 
organizational pressures. They also provided informal guidance which was facilitated by locating themselves in closer proximity to where customer service workers were seated. Learning from social workers was described by customer service workers as central to pursuing more helpful conversations with people seeking assistance.

We had the opportunity then to research, because you don't know what's out there... time to research, build relationships with community providers, and obviously social work. Right from the start we had regular one on ones, reflective, and we used those sessions as educational. (Jenny, Customer Service Worker)

Coaching from social workers took the form of one hour weekly sessions which were focused on allowing customer service workers to reflect on their conversations with customers and how they had pursued supportive referrals where customers expressed additional needs. These sessions appeared to be highly prized by customer service workers.

...we bring in a couple [of examples] and talk about how the conversation went, a question we might have used, what was useful and what might have been better... Trying to identify ways of helping the customer...I'd never experienced that before, here [in Centrelink]. (Luke, Customer Service Worker)

For social workers, coaching sessions and observations from working together began to reveal a change in the way customer service workers assisted people seeking assistance.

I think one of the things I notice about the conversations they are having now compared to what they were having before is that they are more genuine... There is something about it that is not as transactional... (Christopher, Social Worker)

Pursuing such conversations invoked some anxieties for customer service workers which were reduced through close contact with a social worker.

I was really anxious when I first started. I was so worried [laughs]. I didn't know whether I should come in on the first Monday... It helped to spend time with the social worker. (Renee, Customer Service Worker)

Consultations, coaching and training from social workers were viewed as a source of security and support, particularly where these helped build knowledge about other services which they could refer to.

Referrals? I was almost fearful of them... it was like who do I call? It was like a minefield... Whereas now, obviously not fearful of it and I generally have a basic understanding of what they offer, so I'm more confident. (Jenny, Customer Service Worker)

The growing relationship was also significant for allaying customer service workers' discomfort around challenging or distressing experiences arising in their work.

Pretty much anything that would make me feel uncomfortable, personally uncomfortable, I would be straight to a social worker... if I just have any worry about a customer's wellbeing or others. (Mary, Customer Service Worker)

\section{Risks, worries and challenges}

Despite positive experiences, there were challenges around maintaining regular support, and how support was perceived. This was particularly evident in site (A) where local management was seen as limiting opportunities for customer service workers to spend time reflecting with social workers or visiting services with them after the initial training period. Whilst there were perceptions of stronger management support in the other site (B), in both sites, session regularity fluctuated over time with shifts in managers and social worker availability. 
In site $\mathrm{A}$, restrictions on time with social workers impacted opportunities to develop a better sense of community assistance options, something which customer service workers found particularly difficult as it limited their ability to make informed, quick referrals.

The social workers have been really good, they've got a greater awareness, and are handy to at least have a case consultation with... [but there is a] difference between the talk of what it should look like and how it's turning out. It's hopefully something that will change a bit more... at least knowing the [community] services and what they provide... But I think it's a work in progress because it is a fairly large shift. (Luke, Customer Service Worker)

More involvement with social workers led customer service workers to value the social worker role more highly than before. It also resulted in them missing this when it was less available.

Social workers still provide a lot of support. They don't often sit out the front. They are available a lot to consult with cases and good to talk to around extra services and what's going well or what a customer might need or might be good for them. (Luke, Customer Service Worker)

As customer service workers were able to spend more time with customers, the extent of customers accessing additional support became apparent. Coupled with limited availability of social workers (who found their workloads increased rather than alleviated through working closely with customer service workers), this resulted in many lengthy interactions involving only limited or no consultation with social workers. This was viewed with concern by social workers as exposing customers (and workers) to risk.

The notion of risk was discussed in two ways. First, it invoked an objectifying terminology, which might be viewed as a legitimate professional assessment, or more critically, as reductionist and controlling (Rogowski, 2010). Second, talk about risk indicated a broader concern or worry (Seikkula \& Arnkil 2006) at confusion around professional boundaries and at social workers' capacity to be available to and support workers and customers. It was also acknowledged that customers' needs may have previously been overlooked or ignored, and that changes were revealing hitherto hidden needs. Where coaching and regular working together failed to occur, social workers' worries increased.
At one stage people requesting to see a social worker were being sent to [customer service workers]. Now that doesn't happen, but there is still a tendency... At times it has been a little bit frustrating in terms of people not understanding why a social worker might do some things. (Michael, Social Worker)

In the site where customer service workers were concerned about connecting with community services, social workers did attempt to support visits by services into the office and advocated for consistent, regular coaching time. This brought the social workers into conversations with managers which involved some conflict and confusion around who was responsible for customer service workers' development.

....We put in place meetings for major players to get together, but that didn't occur...There wasn't enough interest or commitment... It was really difficult for us because we had different managers ....and every week it was a struggle to have reflective sessions. They [customer service workers] were really passionate and enthusiastic when they began... but there were constant struggles [with management]. I've really had to push to get the one on ones happening. (Nicole, Social Worker)

Caught up in this struggle, customer service workers reflected on the critical importance of their connection to the social worker, as 
well as concerns at an ongoing struggle to give new staff entering the team the same opportunity they had.

They [social workers] are our greatest resource, our backbone ... we work together... [but] the new staff coming in... haven't had the involvement and training in the early days that we had... the support of social workers. (Jenny, Customer Service Worker)

In both sites, social workers dealt with multiple turnovers of managers and had mixed success ensuring coaching and consultation occurred, although this was more successful in site B, where they had a longstanding positive relationship with a key manager and with another senior leader involved in other community initiatives reported elsewhere (Hall, Hadson, Boddy, \& Chenoweth, 2014). Where coaching and consultation flourished, social workers concerns diminished and with it some reduction in their workload was reported. Social workers also reflected on their own growth through new relationships with customer service workers.

It has been really interesting for me working in a different way...working with the CSAs [Customer Service Advisors], helping them. You learn more about them personally and how they approach the work...Yourself, you are more exposed, because if you give feedback you invite feedback... that was interesting to learn how I could handle this...to feel comfortable in the middle of the action. (Nicole, Social Worker)

\section{Working 'alongside'}

My biggest concern was whether social workers were being replaced. My greatest learning has been... that's it's not just about responding to everything... but them [customer service workers] working alongside us. There's an exchange ...we work together ...it's a joy. (Christopher, Social Worker)
Over time, fewer concerns about a threat to professional status were evident, particularly for those social workers who spoke about customer service workers as an additional 'pair of hands', and emphasised a shared approach developing.

I think where this is different is in terms of us really working in partnership, so that we are working in ways which are productive...so the client gets something out of it, to empower them. (Nadine, Social Worker)

In later interviews, customer service workers talked about working collaboratively with social workers, with customer service workers handling simpler referrals and social workers dealing with more complex issues.

[A family] were looking to rent privately somewhere better but they couldn't afford the bond...I contacted [the worker] at [community] housing assistance to help with that but referred them to the social worker as they [also] had issues around trying to get one of their children back into their care...and that was affecting them. (Felicity, Customer Service Worker)

A more humanising customer service response was reported by social workers.

For the customers it was amazing to see what level of support they got. There were Centrelink issues and other assistance through services...seeing the difference they were making for people was really encouraging. (Nicole, Social Worker)

Towards the end of the study, there was still scepticism about changes amongst social workers, particularly in relation to resourcing. Despite this, there was also a strong belief in the benefits of working together and that collaboration had helped clarify the different roles and also improve the efficacy of social workers from an 'add on' to part of the frontline service. 
Sitting out the front with them has helped us in supporting staff rather than just being an 'add on' service. It's just been really useful, seeing what goes on out the front rather than just being behind the scenes. Through that process they have also been able to learn from us and understand the differences between what we do and what they do. (Christopher, Social Worker)

\section{Discussion}

Attempts to develop more supportive interactions in Centrelink exposed the frequent situations of hardship and distress Centrelink customers dealt with. Closer relationships with social workers led customer service workers to value social workers for their knowledge and guidance. Customer service workers' initial anxiety and excitement around what they saw as enhancing their knowledge and making a difference gave way over time to a more constructive recognition of challenges in the service environment and talk of the inspiration and interpersonal support social workers provided. Getting to know the social worker was described as essential, and the capacity to consult with or hand situations over immediately to a social worker reduced worries around complex situations.

Social workers' more sceptical attitude, particularly early on, is understandable in light of the paucity of resources and expectations that they would simply make do. Their growing involvement in situations at the frontline resulted in a mixture of hope and worry. They saw real benefits in working with customer service workers but were concerned about the level of support needed in new arrangements. However, over time customer service workers were equally unhappy about limitations around their access to social workers, and the failure to adequately resource social workers became a shared worry. Towards the end of the study this worry was evident in our interviews with senior managers, and influenced an alternative Centrelink programme which resourced additional social workers to work with customer service outreach staff.

In spite of the struggles and confusion at an organizational level, reforms to the process of customer service delivery led to widespread learning, development and further innovation. Community forums fostering service user feedback to staff were facilitated. These occurred particularly where social workers managed to develop close relationships with customer service staff. Availability and closer relationships between social workers and customer service workers were more evident during the training and settling in period and where social workers were successful in ensuring shared learning activities such as regular coaching and visits with community services. Where such opportunities developed, positivity and even 'joy' around collaboration signified a remarkable (if fragile) shift in organizational practice.

\section{Implications}

Promises of social workers conquering overwhelming organizational challenges have been deservedly critiqued by Marston and McDonald (2012). However, the possibility of guiding others, working with and learning from them, invokes a more balanced picture of how social workers can influence (within limits) in difficult organizational settings. Osborne and Brown (2013) have argued that innovation in public service organizations is increasingly recognised as developed by leaders who engage with networks and value collaborative relationships. Folgheraiter (2004, p.132-134), in picturing social work as an "adventurous journey", highlighted its strength in developing new relationships and providing guidance in changing, challenging welfare environments (Hughes \& Wearing, 2013, pp.197-8).

Social workers are well positioned to provide guidance where challenges arise. First, 
because they are continuously involved in the journeys of other people (Folgheraiter, 2004, p.134) from whom they can learn and draw inspiration (Dybicz, 2012), and also because they can recognise the troubles of people they encounter as public issues. Because of this, guidance which involves an alliance of mutual respect and dialogue with others is most relevant to social work (Maidment, 2006). However, pursuing this in an organizational context, particularly in constrictive welfare organizations is not straightforward. To rephrase Marx's famous dictum, social workers make their own history, but not just as they please or under circumstances of their own choosing.

\section{The politics of relational practice}

New relationships traced in this paper engaged social workers with customer service workers who were a first point of contact with 'the real problems of people in flesh and blood' (Folgheraiter, 2004, p.144). Social workers broadened their own understanding as challenging situations arose which revealed the limitations and obfuscations of the customer service environment. For social workers, changes led to some worries (for themselves, workers and customers), which they expressed in terms of risk. However, they also found changes encouraging and enlightening. New worker relationships threw into relief historical arrangements in the office environment where social workers had been isolated, with limited possibilities for dialogue with customer service workers.

Findings from the Centrelink case suggest that social workers' own 'room to move' (McDonald \& Marston, 2006, p. 171) is expanded through their room to relate. Rather than a straightforward exercise of professional power, social workers' influence in Centrelink was diffuse and linked to the perceptions and development of other workers, and, crucially, to their own learning. Alliances expanded the freedoms of the practice space (Hyslop, 2011, p. 419), and a more humanizing frontline approach was identified, albeit without sufficient resources for change to be consistently maintained.

\section{Conclusion}

The call for social workers to develop a "relational heart" in service provision has grown in strength in recent years (Spratt et al., 2014, p. 1508). In part this has focused on asserting the value of therapeutic social worker-client relationships (Ruch, Turney \& Ward, 2010; Trevithick, 2014). This paper provided an alternate focus on the development of guidance to other workers, reflecting an increased interest in how guidance within a network of relationships contributes to social work (Robertson \& Haight, 2012; Scourfield, 2013).

There is a temptation to view late modern human service environments as straitjacketing social work. This frames social workers as increasingly surrounded by constrictions, with less 'room to move', less discretion and little capacity to influence organizational surroundings. This paper suggests a more nuanced picture, in line with the view of social work as "a perpetually changing and unfinished project" (Adams, Dominelli and Payne, 1998, p. xvi). In this picture, (new) relationships, guidance and inspiration can develop which humanise service provision alongside the difficulties of an adventurous journey involving adversity and (self) discovery.

\section{References}

Adams, R., Dominelli, L., \& Payne, M. (Eds.). (1998). Social work: Themes, issues and critical debates. Basingstoke: Macmillan.

Australian Department of Human Services. (2013). Using strengths and building relationships. Canberra: Australian Department of Human Services.

Dearman, P. (2005). Computerized social casework recording: Autonomy and control in Australia's income support agency. Labor Studies Journal, 30(1), 47-65. http://dx.doi.org/10.1353/lab.2005.0026

Diaz, L. (2008). Social work in Centrelink: Inside out of outside in? In J. R. Owen \& F. Khavarpour (Eds.), Voices from the coalface: Practitioner perspectives about the nature and challenges of community-based work. (pp. 91-101). Champaign, Illinois: Common Ground. 
Dybicz, P. (2012). The hero(ine) on a journey: A postmodern conceptual framework for social work practice. Journal of Social Work Education, 48(2), 267-283.

Eardley, T., Brown, J., Rawsthorne, M., Norris, K., \& Emrys, L. (2005). The impact of breaching on income support customers: Final report. Sydney: Social Policy Research Centre.

Flyvbjerg, B. (2006). Five misunderstandings about casestudy research. Qualitative Inquiry, 12(2), 219-45. http://dx.doi.org/10.1177/1077800405284363

Folgheraiter, F. (2004). Relational social work: Toward networking and societal practices. London: Jessica Kingsley.

Global Agenda for Social Work and Social Development. (2014). Asia-Pacific region. International Social Work, 57, 25-30. http://dx.doi.org/10.1177/0020872814531882

Hall, G., Boddy, J., \& Chenoweth, L. (2014). In the shadow of Rashomon: Pursuing polyphony in practice case studies within the Australian social security environment. Nordic Social Work Research, 4(S1), 102-119. http://dx.doi.org/ 10.1080/2156857X.2014.928646

Hall, G., Hadson, D., Boddy, J., \& Chenoweth, L. (2014). Talking with teen parents, hearing young families: (In) forming welfare reform through local relations. Child \& Youth Services, 35(3), 255-272. http://dx.doi.org/10.1080/ $0145935 X .2014 .938737$

Hall, G., Boddy, J., Chenoweth, L., \& Davie, K. (2012). Mutual benefits: Developing relational service approaches within Centrelink. Australian Social Work, 65(1), 87-103. http://dx.doi.org/10.1080/0312407X. 2011.594956

Howard, C. (2012). The contradictions of individualized activation policy: Explaining the rise and demise of One to One Service in Australia. Critical Social Policy, 32(4), 655-676. http://dx.doi.org/10.1177/0261018311430456

Hughes, M., \& Wearing, M. (2013). Organisations and management in social work. (2nd ed.). London: SAGE.

Hyslop, I. (2011). Social work as a practice of freedom. Journal of Social Work, 12(4), 404-422. http://dx.doi.org/ $10.1177 / 1468017310388362$

Kafka, F. (1997). The castle. London: Penguin.

Kennedy, M., \& Corliss, M. (2008). Tension at the interface: Exploring employee deviation. Journal of Management and Organization, 14(4), 424-437. http://dx.doi.org/ $10.1017 /$ S1833367200003187

Maidment, J. (2006). The quiet remedy: A dialogue on reshaping professional relationships. Families in Society, 87(1), 115-122. http://dx.doi.org/10.1606/1044-3894.3491

Marston, G., \& McDonald, C. (2012). 'Getting beyond 'heroic agency' in conceptualizing social workers as policy actors in the Twenty-First Century'. British Journal of Social Work, 42, 1022-1038. http://dx.doi.org/10.1093/ bjsw/bcs062

McCashen, W. (2005). The strengths approach: A strengths based resource for sharing power and creating change. Bendigo: St Lukes Innovative Resources.

McDonald, C., \& Chenoweth, L. (2009). (Re) shaping social work: An Australian case study. British Journal of Social Work, 39(1): 144-160. http://dx.doi.org/10.1093/bjsw/ bcm094

McDonald, C., \& Marston, G. (2006). Room to move? Professional discretion at the frontline of welfare-to-work. Australian Journal of Social Issues, 41(2), 171-182.
Miles, M. B., \& Huberman A. M. (1994). Qualitative data analysis: An expanded sourcebook. Thousand Oaks, CA: SAGE.

Murphy, J., Murray, S., Chalmers, J., Martin, S., \& Marston, G. (2011). Half a Citizen - Life on welfare in Australia. Sydney: Allen and Unwin.

Osborne, S. P., \& Brown, L. (Eds.). (2013). Handbook of innovation in public services. Cheltenham: Edward Elgar Publishing.

Robertson, A.S., \& Haight, W. (2012). Engaging child welfare-involved families impacted by substance misuse: Scottish policies and practices. Children and Youth Services Review, 34, 1992-2001. http://dx.doi. org/10.1016/j.childyouth.2012.06.006

Rogowski, S. (2010). Social work: The rise and fall of a profession. Bristol: Policy Press.

Ruch, G., Turney, D., \& Ward, A. (2010). Relationshipbased practice: Getting to the heart of practice. London: Jessica Kingsley Publishers.

Scourfield, P. (2013). Even further beyond street-leve bureaucracy: The dispersal of discretion exercised in decisions made in older people's care home reviews. British Journal of Social Work, 45(3), 914-931. http://dx.doi.org/10.1093/bjsw/bct175

Seikkula, J., \& Arnkil, T (2006). Dialogical Meetings in Social Networks. London: H. Karnac.

Spratt, T., Nett, J., Bromfield, L., Hietamäki, J., Kindler, H., \& Ponnert, L. (2014). Child protection in Europe: Development of an international cross-comparison model to inform national policies and practices. British Journal of Social Work, 45(5), 1508-1525. http://dx.doi. org/10.1093/bjsw/bcu109

Tonkens, E., \& Verplanke, L. (2013). When social security fails to provide emotional security: Single parent households and the contractual welfare state. Social Policy and Society, 12(3), 451-460. http://dx.doi. org/10.1017/S1474746413000110

Trevillion, S. (1999). Networking and community partnership. Aldershot: Ashgate.

Trevithick, P. (2014). Humanising managerialism: Reclaiming emotional reasoning, intuition, the relationship, and knowledge and skills in social work. Journal of Social Work Practice, 28(3), 287-311. http://dx.doi.org/10.1080/ 02650533.2014 .926868 